\title{
MÉXICO BAJO LA MEDICIÓN \\ DE LA COMPETITIVIDAD A NIVEL GLOBAL: \\ CARACTERÍSTICAS Y PROBLEMAS
}

\section{Eduardo Ramírez Cedillo ${ }^{1}$}

\section{Alejandra A. Ibañez Tercero ${ }^{2}$}

\section{Resumen}

La medición de la competitividad es necesaria en cualquier empresa o país, a medida que ha avanzado el proceso de globalización es importante establecer índices que midan la competitividad y que puedan ser comparables, el índice debe ser un buen indicador que ayude a los países a conocer qué hacen bien y en dónde se abren oportunidades de mejora. En este sentido, un índice que se ha mantenido en el tiempo y que aporta información valiosa en la materia es el Índice de Competitividad Global (ICG) en el cual México a lo largo de los años ha perdido posiciones. En virtud de lo anterior el presente documento tiene por objetivo establecer algunos de los problemas a los que se enfrenta el país para mejorar sus niveles de competitividad de acuerdo con las métricas del ICG.

Palabras claves: Competitividad, Productividad, ICG, México

\begin{abstract}
The measurement of competitiveness is necessary in any company or country, as the process of globalization has progressed, it is important to establish indexes that measure competitiveness and that can be comparable, it should be an indicator that helps countries to know that they do well and where opportunities for improvement are opened. In this sense, an index that has been maintained over the time and which provides valuable information on the subject is the Global Competitiveness

1 Profesor-Investigador en la Universidad Autónoma Metropolitana, Unidad Iztapalapa, miembro del sistema nacional de Investigadores nivel I.

2 Analista privado.
\end{abstract}


Index (ICG) in which Mexico has lost positions over the years. In this way, this document aims to establish some of the problems that the country is facing in order to improve its levels of competitiveness according to ICG metrics.

Key words: competitiveness, productivity, GCI, Mexico.

\section{Introducción}

Hablar de competitividad es algo común en nuestros días, el término se ha vuelto cotidiano y quizás, incluso, ha perdido sentido y magnitud al usarse de forma simplista. Ser competitivo implica mantener los niveles de productividad al menos a la par de la competencia y, en el mejor de los casos, por arriba de ellos. La productividad es el resultado preferentemente del mejoramiento de los factores de producción, tal es el caso del capital y del recurso humano ${ }^{3}$.

Si bien es cierto que la productividad y la competitividad tienen una relación muy estrecha, según Porter $^{4}$, cada una es diferente entre sí; mientras que la primera es un indicador que refleja qué tan bien se están usando los recursos de una economía en la producción de bienes y servicios, es también la que refiere una relación entre recursos utilizados y productos obtenidos y denota la eficiencia con la cual los recursos (humanos, capital, conocimientos, energía, entre otros) son usados para producir bienes y servicios en el mercado. Según Levitan (1984), la segunda es la capacidad para sostener e incrementar la participación en los mercados internacionales, con una elevación paralela del nivel de

3 La dinámica entre los factores es diferente, mientras el capital avanza de forma rápida, y en ocasiones exponencial, el recurso humano es más estático y tiene mayores limitaciones. En ambos casos la inversión puede mejorar su condición.

4 El concepto de competitividad expresado por Michael Porter en su obra llamada La ventaja competitiva de las naciones (1991), menciona que la competitividad está determinada por la productividad, definida como el valor del producto generado por una unidad de trabajo o de capital. La productividad es función de la calidad de los productos y la eficiencia productiva, destacando que la competitividad se presenta en industrias específicas y no en todos los sectores de un país. 
vida de la población. El único camino sólido para lograrlo se basa en el aumento de la productividad (Porter, 1991).

A nivel de país parece complejo establecer qué tan competitivo se es. Sin embargo, se pueden utilizar diferentes métricas para intentarlo. Una de ellas es comparar las tasas de crecimiento económico (por niveles o per cápita), pero ello solo se centraría en el resultado sin conocer los elementos que lo propician. Otra forma consiste en comparar variables que inciden en el crecimiento y analizar su comportamiento a través del tiempo, la dificultad de este proceder estriba en las ponderaciones que se tendrían que establecer y los niveles a considerar.

A pesar de ello, estas dificultades han sido superadas por el Índice de Competitividad Global (ICG), en la práctica ha generado una metodología robusta que permite valorar de forma rápida qué países han avanzado en materia de competitividad y quiénes se han rezagado; es también una herramienta para entrar al conocimiento de los diversos temas que este índice incluye dentro de su metodología y estar en condiciones de valorar lo que se hace en cada país y lo que se tendría que hacer para mantener un perfil de competencia.

En virtud de lo anterior el presente documento tiene por objetivo analizar el desempeño del país de conformidad con las métricas del ICG y detallar en algunos casos, de acuerdo con el desglose de dicho índice, cuáles son los temas en los que se tienen dificultades y que impiden un mejor desempeño en materia de competitividad y, por ende, en el crecimiento económico. Para tal fin lo que resta del escrito se integra por II) una descripción sucinta del ICG, para continuar III) con una revisión del país y establecer en dónde se ubica México en materia de competitividad y en qué condiciones está de IV) establecer cuáles son algunos de los problemas que enfrenta el país en dicha materia, posteriormente se ofrecen algunas conclusiones al respecto.

Antes de dar paso a los temas mencionados es importante comentar las limitaciones que se tienen en el presente trabajo al tratar de plantear una visión amplia del desempeño de la economía mexicana, usando para ello el ICG. La primera de ellas se desprende de los múltiples y diferentes 
problemas que pueden ser ilustrados en la realidad que vive el país, de doce pilares que componen al ICG por lo menos se tienen dificultades serias en cinco de ellos. La segunda limitación aparece por la amplitud de los pilares mencionados lo que obliga a una redacción más descriptiva que analítica, con la intención de evidenciar a qué se debe el mal resultado dentro del ICG. No obstante, la importancia del documento consiste en poner en evidencia la relevancia de índices como el ICG que posibilitan una perspectiva clara de los avances o retrocesos que tienen los países y cómo mediante esta identificación se puede proceder a buscar las causas y propiciar las condiciones para realizar propuestas de política.

\section{2. Índice de Competitividad Global (Foro Económico Mundial)}

El Informe de Competitividad Global analiza la competitividad de 138 economías al año 2015, llevando dicho estudio a través de 110 indicadores que provienen de fuentes oficiales nacionales e internacionales, procedentes de encuestas de opinión (principalmente la Encuesta de Opinión Ejecutiva ${ }^{5}$ ) realizadas a más de 12 mil líderes empresariales en todos los países.

Dicho informe se encuentra basado en el Índice de Competitividad Global (ICG), el cual toma en cuenta políticas, factores e instituciones que determinan el crecimiento económico de los países, dicho índice muestra, a través de subíndices, a los países desarrollados y a los países en vías de desarrollo, sobre los cuales influye la productividad, el ingreso, el acceso a oportunidades, entre otros factores, del tipo económico, político y social.

5 La EOE constituye uno de los componentes principales del Informe y es el elemento clave para que éste sea una medición anual representativa del entorno económico de una nación y su capacidad para alcanzar un crecimiento sostenido. La EOE reúne información valiosa sobre una amplia gama de variables para los cuales los datos rigurosos y fiables son escasos o inexistentes. Los indicadores de la EOE están dados en una escala del 1 al 7, donde 1 indica que es la posición más desfavorable para el indicador y 7, la más favorable (ICG, 2015). 
El ICG identifica tres grandes factores que son determinantes para la competitividad:

- Requerimientos Básicos: considera los elementos y/o condiciones básicas que cada país necesita para ser competitivo y tiene que ver con las instituciones, la infraestructura, el ambiente macroeconómico, salud y educación primaria.

- Promotores de Eficiencia: como su nombre lo dice son los factores que sirven para proveer de eficiencia al país en torno a la competencia y el buen manejo de la economía, los cuales son, educación superior y capacitación, eficiencia en el mercado de bienes, eficiencia en el mercado laboral, sofisticación del sistema financiero, preparación tecnológica y el tamaño del mercado.

- Factores de la Innovación y la Sofisticación: este subíndice tiene que ver en la forma en cómo las empresas de la economía en cuestión se desempeñan y cómo influyen para hacerla más competitiva a través de la sofisticación de negocios y la innovación.

El índice considera que cada país se va desarrollando dependiendo de la manera en que se desenvuelve a través de estos factores y los pilares que se encuentran dentro de cada uno. Es importante tomar en cuenta que el nivel de productividad es un elemento que establece prosperidad, es la habilidad de un país de mejorar su nivel de vida en el tiempo, al aumentar el producto por trabajador (Krugman, 2004:85); a su vez determina el nivel de competitividad en una economía que consiste principalmente en el incremento de la participación en los mercados internacionales, elevando, al mismo tiempo, la calidad de vida de la población, el camino para lograrlo es por medio del aumento de la productividad (Porter, 1990:50).

La productividad, su implementación y el papel que lleva a cabo en los países han sido el punto de partida de diversos estudios de economistas neoclásicos, desde Adam Smith, pero, debido a la configuración de la economía mundial y las necesidades de los habitantes, se han integrado factores como educación, salud, tecnología, entre muchos otros, 
que influyen directa o indirectamente en el desempeño de la productividad y la competitividad.

\section{Países sobresalientes}

El cuadro 1 presenta a los doce países que figuran como primer lugar en todos y cada uno de los pilares correspondientes al ICG 2016, así también se incluyen los subíndices con el respectivo país y la calificación que los coloca en primer lugar.

Algo interesante del cuadro 1 es que, en el subíndice relativo a factores de la innovación y sofisticación, Suiza es el país con el mejor desempeño tanto en dicho subíndice como en los pilares 11 y 12 que lo componen, no así en los otros dos subíndices. En el caso del subíndice de requerimientos básicos el país con el mejor desempeño es Singapur, aun cuando en ninguno de los pilares que lo componen aparece como el mejor evaluado, en los pilares 1, 2 y 4 aparece en segundo lugar, mientras que en el pilar 3 lo hace en la onceava posición (puntaje de 6.10, $6.50,6.15$ y 6.75 respectivamente). Por su parte, Finlandia tiene un excelente desempeño en los pilares 1 y 4 , en donde ocupa el primer lugar, pero en los pilares 2 y 3 se encuentra en la posición vigésima sexta y cuadragésima sexta (puntajes de 6.13, 5.34, 5.14 y 6.89 respectivamente), con esos números Finlandia queda en el décimo segundo lugar del subíndice con un puntaje de 5.88 .

\section{Cuadro 1. Los países más destacados a nivel mundial del ICG 2016}

\begin{tabular}{|c|c|c|c|}
\hline $\begin{array}{c}\text { Subíndice, País } \\
\text { y Calificación }\end{array}$ & Pilar & País & Calificación \\
\hline \multirow{3}{*}{$\begin{array}{c}\text { Índice de Reque- } \\
\text { rimientos Básicos } \\
\text { Singapur 6.4 }\end{array}$} & 1. Instituciones & Finlandia & 6.1 \\
\cline { 2 - 4 } & 2. Infraestructura & Hong Kong SAR & 6.7 \\
\cline { 2 - 4 } & 3.Estabilidad macroeconómica & Noruega & 6.8 \\
\hline
\end{tabular}




\begin{tabular}{|c|c|c|c|}
\hline \multirow{4}{*}{$\begin{array}{c}\text { Índice de Promo- } \\
\text { tores de Eficiencia } \\
\text { Estados Unidos } \\
\mathbf{5 . 8}\end{array}$} & $\begin{array}{c}\text { 5. Educación Superior } \\
\text { y Capacitación }\end{array}$ & Singapur & 6.3 \\
\cline { 2 - 4 } & $\begin{array}{c}\text { 6.Eficiencia en el mercado } \\
\text { de bienes }\end{array}$ & Singapur & 5.8 \\
\cline { 2 - 4 } & $\begin{array}{c}\text { 7. Eficiencia en el mercado laboral } \\
\text { f.Sofisticación del sistema } \\
\text { financiero }\end{array}$ & Sueva Zelanda & 5.8 \\
\cline { 2 - 4 } & 9. Preparación tecnológica & Suiza & 6.4 \\
\cline { 2 - 4 } $\begin{array}{c}\text { Índice de Facto- } \\
\text { res de innovación } \\
\text { y sofisticación } \\
\text { Suiza 5.8 }\end{array}$ & 11. Sofisticación de los Negocios & Suiza & 7.0 \\
\cline { 2 - 4 } & 12. Innovación & Suiza & 5.8 \\
\hline
\end{tabular}

Fuente: Elaboración propia con base en el ICG, 2016.

Algo similar ocurre con la economía estadounidense, economía que aparece como el primer lugar en el subíndice de promotores de eficiencia con un puntaje de 5.8, no obstante, en ninguno de los pilares aparece con el primer lugar. Singapur encabeza el pilar 5 y 6, Suiza el 7 y 9 , Nueva Zelanda el 8 y China el pilar 10, en cada caso el puntaje obtenido fue menor que el de los Estados Unidos. Singapur obtuvo un puntaje de 5.73 ocupando el segundo puesto solo detrás de Estados Unidos, Suiza obtuvo un puntaje de 5.62 quedando en el tercer lugar, Nueva Zelanda 5.38 ocupando la posición 8 y por último China con un puntaje de 4.79 que deja a esa economía en la trigésima posición. En el agregado los Estados Unidos presentan el mejor resultado con un puntaje de 5.88, lo que lo coloca en la primera posición.

El índice arroja que el común denominador entre estos países consiste en la búsqueda constante de su competitividad, misma que se refleja en los pilares relacionados a instituciones públicas y privadas que operen adecuadamente y en conjunto, en donde existe infraestructura desarrollada en todos los niveles, un marco macroeconómico estable y una fuerza de trabajo saludable y educada desde las primeras etapas escolares.

Estas economías consideran que sus dependencias y organismos deben funcionar bajo características de transparencia, equidad, estabilidad 
y eficiencia, tanto a nivel macroeconómico, como a nivel microeconómico, lo que permite un mejor posicionamiento de competitividad a nivel internacional.

Una característica distintiva de las economías competitivas es la interacción fluida y constante entre las compañías, instituciones y entidades del gobierno. Cuando existe una comunicación flexible entre los participantes hay más probabilidad de que las regulaciones públicas se basen en la inquietud por la competitividad (Porter, 2001:3).

Por su parte, los países en vías de desarrollo en lo general se ubican en alguna etapa de transición, buscando acoplarse de manera rápida a los cambios que la globalización produce y muchas de sus actividades se centran en satisfacer las necesidades de las economías desarrolladas proveyéndolas de bienes y servicios.

Un ejemplo de economías en vías de desarrollo son los países de Latinoamérica que, de acuerdo con Estrada y Landa (2012), mantienen un proceso gradual de reconversión comercial, en el que persiste un esquema comercial de importador neto de bienes de alta tecnología y exportador neto de bienes basados en recursos naturales o con bajo-medio contenido tecnológico. Ejemplo de ello es el caso de México, donde la exportación manufacturera representa el 81.9\% del total de las exportaciones, aunque el perfil de esta plataforma de exportación está apuntalado en un reducido grupo de industrias que, sea por el alto grado de sofisticación tecnológica de algunos sectores o por el comprimido nivel tecnológico de otros, crean escasos vínculos productivos (Landa y Arriaga, 2017).

Sin embargo, ya sean plataformas de producción y comercialización grandes o pequeñas, el desenvolvimiento de los países en vías de desarrollo debe llevarse a cabo de tal forma que encuentren la manera de relacionarse con economías en desarrollo, y de introducirse en los procesos de globalización. 


\section{La competitividad en México}

De acuerdo a la clasificación por etapas que presenta el World Economic Forum (WEF), México se considera como un país en transición de la etapa 2 (orientación por eficiencia) a la etapa 3 (orientación por innovación). Lo que implica que sus políticas deben perseguir el desarrollo de sus instituciones, la ampliación y mejoramiento de la infraestructura, mejorar la calidad en los servicios de salud y educación, además de estimular el mercado laboral.

El desarrollo de una auténtica competitividad requiere de políticas elaboradas e implementadas por los gobiernos, tomando en cuenta elementos de innovación tecnológica y educación. Atendiendo a su vez los aspectos institucionales, que son importantes dentro del entorno en el cual se desarrollan las empresas (Suñol, 2006).

En el cuadro 2 se presentan los datos socioeconómicos más importantes de México respecto de las necesidades del trabajo, incluyendo la población, la pobreza, el Índice de Desarrollo Humano (IDH) y el PIB.

\section{Cuadro 2. Perfil socioeconómico de México, 2016}

\begin{tabular}{|c|c|}
\hline $\begin{array}{c}\text { Lugar en el Índice de } \\
\text { Competitividad Global }\end{array}$ & $\begin{array}{c}\mathbf{5 7 / 1 4 0} \text { economías, con una } \\
\text { calificación de } \mathbf{4 . 3}\end{array}$ \\
\hline Población & 127 millones de personas \\
\hline PIB & $1,144.3$ billones de dólares \\
\hline PIB Per cápita & $9,009.28$ dólares \\
\hline Índice de Desarrollo Humano (IDH) & 0.756 a 2014 (Medio) \\
\hline Personas en pobreza & 55.3 millones de personas \\
\hline
\end{tabular}

Fuente: Banco Mundial y CONAPO, 2016.

\section{Los 12 pilares de la competitividad en el caso de México}

El Índice de Competitividad Global para el periodo de 2006 a 2016 (gráfica 1) muestra que México se ha mantenido relativamente estable sin que haya dado un paso definitivo en mejorar su nivel de competitividad. Sobre todo, si se recuerda que 10 años atrás el lugar ocupado den- 
tro del índice estaba en el lugar 37, y en estos años denota la dificultad para lograr superar la barrera del lugar 50 .

Sin embargo, a pesar de que ocupa esta posición, México se encuentra bien ubicado en el índice al ser 138 economías en total; cabe mencionar que no todas las economías pueden mantener el mismo desempeño económico en todos los años, ya que dependen de factores y sucesos externos; México, al ser una economía en desarrollo, depende en gran parte de la evolución de economías como la de Estados Unidos.

\section{Gráfica 1. Índice de Competitividad Global 2006 -2016 (rango y valor)}

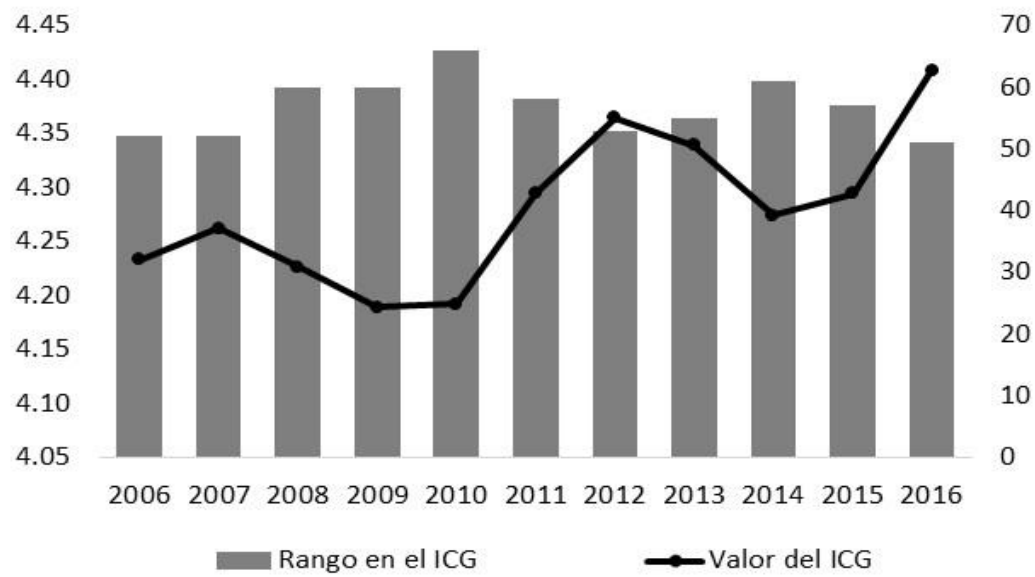

Fuente: Elaboración propia con base en el Índice de Competitividad Global, 2016.

A continuación, se presenta un análisis del resultado obtenido por México de acuerdo con los subíndices y desglosando a cierto detalle cada uno de los pilares, con la intención de tener una idea más completa de dónde están las oportunidades y las restricciones a las que se enfrenta el país. 


\section{Subíndice A: Requerimientos básicos}

La competitividad depende en buena medida del entorno productivo que enmarcan las instituciones, es decir, un ambiente en el cual las empresas puedan desenvolverse con diversos agentes económicos en los mejores términos posibles. De acuerdo con Salas (2005: 47), el desarrollo de un sistema productivo consiste en el desarrollo de factores e instituciones que favorecen las acciones colectivas y que permiten explotar la potencialidad competitiva del sistema, a través del establecimiento y consolidación de relaciones de colaboraciones entre los actores locales.

En 2016, el subíndice de requerimientos básicos obtuvo una calificación de 4.6, lo cual posicionó al país en el número 71 de 138 (en la gráfica 2 se muestra el desglose de los pilares del subíndice A). La principal debilidad se encuentra en el pilar número 1 (instituciones) donde se ocupó el lugar número 116 a nivel mundial, similar a países como Ecuador y El Congo. Una de las problemáticas que aqueja la estabilidad y la confianza de las instituciones es la corrupción, de acuerdo con Casar (2015:45-46), la corrupción es un lastre por los enormes costos económicos, políticos y sociales que ocasiona en los países que la padecen con mayor agudeza, por ello es indispensable identificar y cuantificar dichos costos para conocer la dimensión del problema y diseñar políticas públicas adecuadas para su prevención y erradicación.

En materia de infraestructura, en 2016, se ocupó la posición número 57, similar a países del Medio Oriente como Irak e Irán, entre otros. El problema en este rubro tiene que ver con la cantidad de recursos asignados a tal propósito, tomando en cuenta a los países de América Latina, México se encuentra por debajo de países como Perú y Nicaragua, cuyos promedios oscilaron entre el 4 y el 6 en el periodo de 2008 a 2013. 


\section{Gráfica 2. Evolución del Subíndice A: Requerimientos básicos en México, 2006-2016}

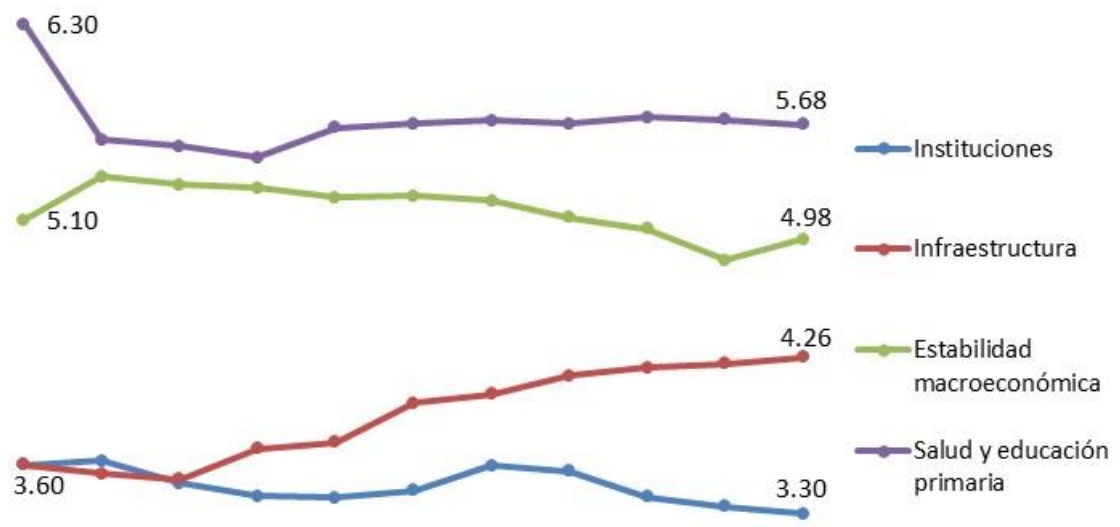

20062007200820092010201120122013201420152016

Fuente: Elaboración propia con base en World Economic Forum, 2015.

La adecuada disponibilidad de obras de infraestructura y la prestación eficiente de servicios conexos, contribuyen a que un país o región pueda desarrollar ventajas competitivas y alcanzar un mayor grado de especialización productiva (Rozas y Sánchez, 2004:7).

\section{Subíndice B: Promotores de eficiencia}

Los promotores de eficiencia están relacionados con aumentar el crecimiento y hacerlo más dinámico a favor de la sociedad y la economía. Este subíndice ocupa una calificación de 4.4 lo que lo coloca en el lugar número 45 en 2016, posición mejorada con respecto a un año antes, la cual fue número 53.

En este caso el ICG de 2006 a 2016 presenta a México como uno de los países con mayor tamaño de mercado a nivel mundial, ocupando la posición número 11 de 138, debido a la dimensión de su mercado interno y el mercado externo, esto se ve reflejado en la gráfica 3, que muestra todos y cada uno de los pilares correspondientes al subíndice en cuestión. 


\section{Gráfica 3. Subíndice B: Promotores de la eficiencia 2006-2016}

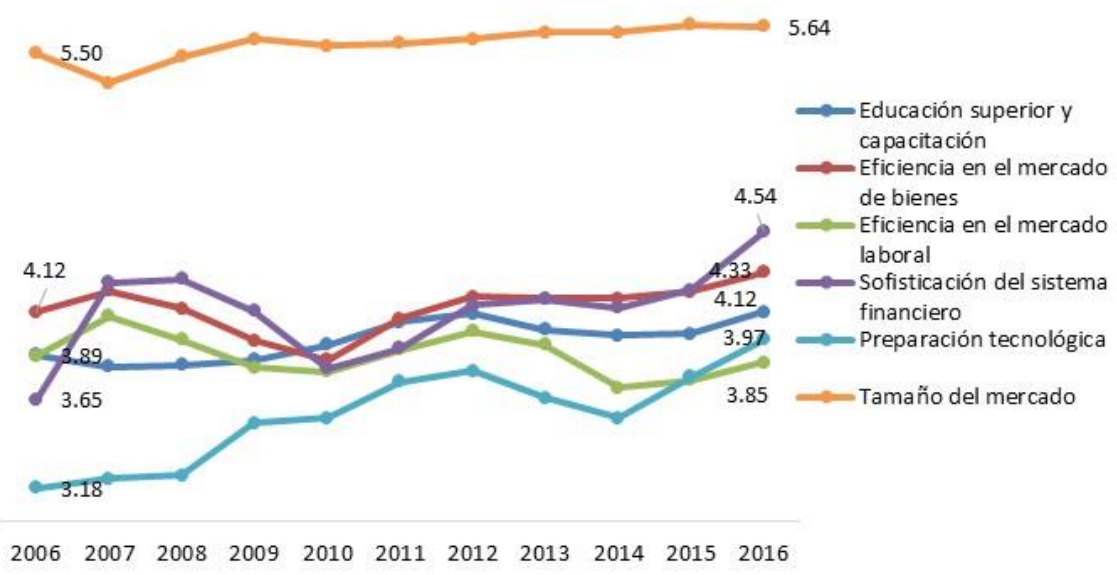

Fuente: Elaboración propia con base en World Economic Forum, 2015.

La globalización se representa con el símbolo de red mundial, una red que permite mayor eficacia en los procesos productivos y el reordenamiento de los modos de trabajo (Brunet y Belzunegui, 2000:43). Para México la productividad es un elemento a favor, pero se desaprovecha por factores que no se vinculan, tal como la preparación tecnológica que se constituye como el uso y disponibilidad de técnicas de información y comunicación, así como la adopción de tecnologías.

\section{Subíndice C: Factores de innovación y sofisticación}

En México y en todo el mundo, la innovación es un factor clave para el crecimiento económico ya que permite aumentar y eficientar la productividad, y con ello la competitividad de las actividades sectoriales, así como beneficios a la sociedad, los consumidores y empresarios; mejoras en productos y servicios, mayor rentabilidad e innovación y, por tanto, un crecimiento económico sostenido (Programa Nacional de Innovación, 2015).

Para 2016, el ICG coloca a la economía mexicana en el puesto número 50, con una calificación de 3.8; mejorando dos lugares respecto del 
año 2015, el comportamiento de dicha economía en cuestión tecnológica es similar a Tailandia.

En economías como México, la innovación y la sofisticación deben ser la punta de lanza para un crecimiento sólido, esto solo resulta de aumentar y distribuir la inversión de manera adecuada en I+D, dentro de un marco estratégico.

La innovación mejora la competitividad de las empresas para hacer frente a un entorno cada vez más competitivo y global, lo que afecta a todas las empresas, no importa que éstas sean grandes o pequeñas, industriales o de servicios (González, 2000:12).

El ICG establece que el subíndice C lleva integrados dos temas que se hacen alusivos al nombre del subíndice, por un lado, el de sofisticación en los negocios y por otro lado la innovación.

En México, de 2006 a 2016, las sofisticaciones en las relaciones de negocios son más propensas a un clima de competitividad y eficiencia en comparación con la innovación, así lo muestra la gráfica 4, en la cual se observa que se ha puesto más prioridad a mejorar las estrategias de las redes comerciales y operacionales de las empresas en una economía, a diferencia de invertir y crear políticas encaminadas a generar fuentes de innovación y tecnología.

Cabe recordar que la competitividad está relacionada con la reconversión industrial y la revolución de los procesos productivos en términos tanto cuantitativos como cualitativos (Arellanes, 1996), esto quiere decir que una empresa no sólo debe producir valor, sino también generar conocimiento y sofisticación en los negocios, por medio de los recursos y políticas disponibles en el país donde se establezca.

Siguiendo con la gráfica 4, se puede ver que, pese a que la participación de actividades de ciencia, tecnología e innovación ha ido en aumento o ha tenido más importancia, no se le ha otorgado prioridad para el desarrollo mayúsculo en ciencia y tecnología, además, no existe un proyecto estricto y preestablecido con logros y metas en tal materia. Lo anterior también tiene que ver con el monto en dinero que cada año 
el gobierno destina a la inversión y desarrollo, así como la capacidad distributiva eficiente de dichos recursos.

En general, el gasto público y privado de México en innovación es de $0.52 \%$ de su PIB, según los últimos datos de Banco Mundial para 2014 , y en materia de ciencia y tecnología el gasto presupuestal asignado fue de $26,963.5$ millones de pesos, correspondiente a un $0.19 \%$ del total del presupuesto asignado en 2017, según el PEF.

\section{Gráfica 4. Evolución del Subíndice C: Factores de innovación y sofisticación, 2006-2016}
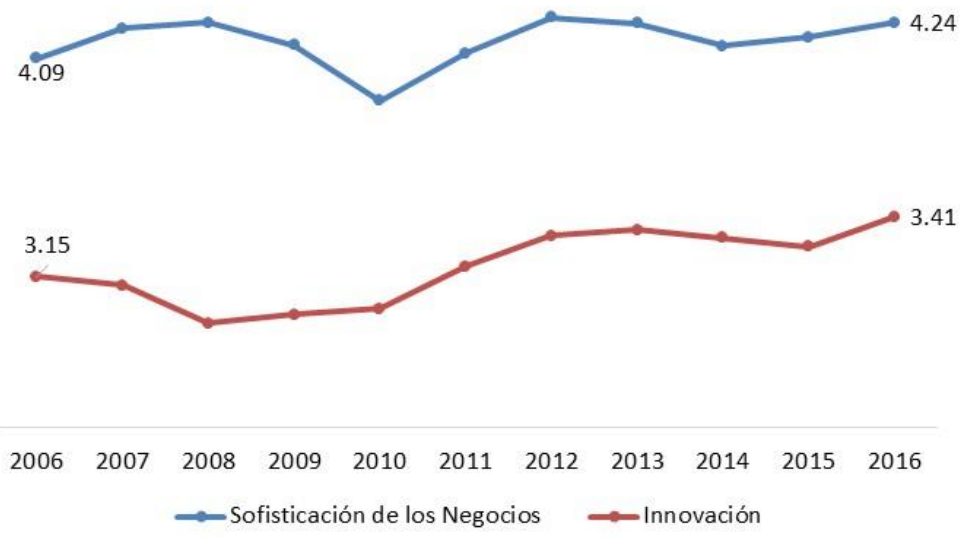

Fuente: Elaboración propia con datos de Secretaría de Educación Pública, 2016.

La educación en México es un derecho fundamental y un bien público, por lo que las políticas deben garantizar su beneficio. Los niveles bajos de educación en México hacen indispensable colocar la reforma educativa entre las prioridades de desarrollo para el Estado Mexicano. Se necesitan políticas públicas de innovación para atender la educación, desarrollando capacidades en la población que puedan responder a los retos que implica la dinámica de la globalización y la sociedad del conocimiento (Peralta, 2011).

Las políticas de gobierno deben consensar un presupuesto para ciencia y tecnología que vaya en aumento no en descenso y que además sea 
un gasto funcional y eficiente, no sólo otorgar recursos por otorgar. Una cuestión fundamental de política pública es cómo se asignan los recursos públicos limitados y qué tan efectivamente se utilizan. Por desgracia en la mayoría de los países en desarrollo los recursos en I+D son limitados y no suelen asignarse o utilizarse de la mejor forma (Vandana, 2012:172).

El nivel de productividad de un país está directamente vinculado a la calidad e impulso que las políticas públicas dan al conocimiento, tanto en su producción como en su difusión (García, 2011: 4).

Se deben cuidar las áreas más débiles y poco desarrolladas ya que éstas pueden ser modificadas para convertirse en áreas de impacto económico, por ejemplo, el sector agrícola al cual se le ha dado poca atención por lo menos en los últimos 40 años.

México ha logrado destacar en áreas con tamaño de mercado amplio, tal es el caso de la industria automotriz, también en la capacidad para hacer negocios y en una inflación estable, entre otros aspectos. Pero se ha rezagado en componentes que son vitales para el desarrollo del país, sobre todo en el tema de la corrupción, vinculado al poco desarrollo institucional, uno de los motivos principales por los cuales México no avanza.

\section{Problemática de México para mejorar su competitividad}

En conformidad con el ICG (2016) de los 12 pilares existentes se escogieron los ocho que poseen menor desempeño en materia de competitividad, tomando en cuenta que son también los que más influyen en la economía. De los ocho se pasó al desarrollo de cinco de ellos, para entender el desempeño y la manera en que éstos se consolidan como una restricción a nivel nacional para alcanzar mejores niveles de competitividad.

Estos cinco son los que de manera general pueden influir más sobre la competitividad de la economía mexicana, los cuales son, por orden de calificación: las instituciones, la infraestructura, la eficiencia en el mercado laboral, la preparación tecnológica y la innovación. No obs- 
tante, lo anterior no significa que los pilares no mencionados no sean importantes o no tengan influencia sobre la economía, aunque los cinco establecidos son, de alguna forma, la punta de lanza que se debe mejorar para poder sacar adelante a México y no sólo en torno a la competitividad sino también a la población y su bienestar.

\section{Instituciones}

El pilar de mayor debilidad en México es el relacionado con las instituciones, el cual, como ya se mencionó anteriormente, tiene una calificación de 3.3 y la posición número 116 de 138 economías, lo que no resulta novedoso pues de forma cotidiana se conocen anomalías en el cumplimiento de las obligaciones que tiene el Estado con la sociedad, y eso aunado a los niveles de impunidad genera condiciones poco propicias para ampliar la competitividad.

Según el WEF, el ambiente económico es determinado por el marco normativo, legal y administrativo, en donde los ciudadanos, el gobierno y las empresas interactúan para crear ganancia y bienestar general, una vía para llegar a ello es por medio de las instituciones. North (1990) cita a las instituciones como restricciones que surgen de la invención del ser humano para limitar las interacciones políticas, económicas y sociales, incluyendo las restricciones informales tales como sanciones, costumbres, tradiciones, códigos de conducta y las reglas formales que pueden ser la constitución, las leyes, los derechos, entre otras.

Mientras que Gallino (1993), menciona que el término de institución generalmente encierra la idea de complejos normativos que regulen los comportamientos de los individuos aludiendo a aspectos relevantes de la vida social, reduciendo las alternativas abiertas a los sujetos y con ello la complejidad y la contingencia de la sociedad.

Asimismo, a las instituciones también se les pueden aludir algunos elementos, por ejemplo, que tienen una duración temporal (mayor respecto a los individuos), son modelos de comportamiento dotados de normatividad y cuya dinámica es resultado de la intersección de proce- 
sos espontáneos y queridos, que reflejan las necesidades y los requisitos funcionales de la sociedad (Cavalli, 1996).

Las instituciones surgen a través de la historia para crear y vigilar que las interacciones entre ciudadanos, gobierno y empresas se den de manera ordenada, así también para dar dirección eficiente a los cambios económicos que se presentan a diario en una economía, tanto en vías de desarrollo y desarrolladas. Para llevar a cabo el propósito, cada institución está constituida por reglas, formas, normas informales y las características ejecutables, formalizados por la política, la cual es la que da certeza y respaldo a dichos elementos.

Sin embargo, en México las instituciones no suelen ser tan eficientes al presentar algunas de las siguientes problemáticas:

- No guardan una estructura interna definida.

- No existe una relación con la sociedad con base en sus necesidades.

- La falta de ética, la corrupción y la seguridad son los tres problemas que más aquejan a las instituciones.

- No existe un sistema o entidad que identifique de manera certera los actos de corrupción.

- La participación ciudadana (la voz de la ciudadanía) dentro de las instituciones es baja o nula.

Las instituciones son y deben ser una pieza clave para el crecimiento y la competitividad, ya que influyen sobre las políticas de comercio, inversión y producción de empresas nacionales e internacionales. Pero, a medida que la economía se amplía, existe mayor regulación, la burocracia, el papeleo, la falta de honradez y transparencia, los pagos excesivos de trámites, entre otras situaciones, se va mermando el objetivo crucial de cada institución, dejando incapacidad para proporcionar servicio adecuado en tiempo y forma, de acuerdo a las actividades de cada institución, afectando de manera directa a la sociedad en su conjunto, empresarios, ciudadanos, el mismo gobierno, y más aún, en diversos temas de la vida cotidiana. 
Desde una perspectiva censal, Consulta Mitofsky llevó a cabo la encuesta llamada, México: confianza en instituciones $2016^{6}$, en donde se refleja que la población confía de la siguiente forma:

De las 17 instituciones medidas ${ }^{7}$, al tener disminuciones, hay pocos cambios destacando los sindicatos que pasan del lugar 13 al 16; la $\mathrm{Su}-$

En 2015 las Universidades (7.3), la Iglesia (7.1) y

Confianza Alta el Ejército (7.0) eran instituciones que los ciudadanos consideraban ampliamente confiables, sin embargo, en 2016, sólo las universidades (7.1) es la única institución en quien confían los mexicanos.

De las 17 instituciones medidas casi la mitad se encuentra en la categoría de Confianza Media, desde la Iglesia (6.9), el Ejército (6.8), las cuales pasaron a ser de categoría alta a categoría media; la Comisión Na-

Confianza Media cional de los Derechos Humanos (6.6), las estaciones de radio (6.4), los medios de comunicación (6.3), los empresarios (6.2), el Instituto Nacional Electoral (6.2) y los Bancos con 6.1.

Sube de seis a ocho el número de instituciones en este grupo con respecto a 2015, siendo las dos instituciones

Confianza Baja con menor confianza los sindicatos (4.9) y los partidos políticos con 4.8.

prema Corte de Justicia de la Nación del lugar 8 al 11, y al revés el INE que en la medición anterior se ubicó en el puesto 11, este año mejoró y se ubicó en el lugar ocho.

6 México: Confianza en Instituciones 2016, encuesta nacional en viviendas, octubre de 2016, Consulta Mitofsky. La calificación va de 0 a 10 en donde 0 es la menos confiable y 10 la más confiable; para 2016 la calificación 6 fue la del promedio, si la institución tiene una calificación menor a 6 entonces se encontrará en el nivel de confianza baja.

7 Universidades, Iglesia, Ejército, CNDH, Estaciones de radio, Medios de comunicación, Empresarios, SCJN, Bancos, Cadenas de televisión, INE, Presidencia, Sindicatos, Senadores, Política, Diputados y Partidos políticos, en orden de confianza, según la encuesta de consulta Mitofsky 2015. 
La institución encargada de guardar la seguridad de los ciudadanos mexicanos es de las que menor confianza tiene, lo cual va de la mano con datos de INEGI plasmados en la Encuesta Nacional de Victimización y Percepción sobre Seguridad Pública (ENVIPE) 2015, que se encarga de identificar a la policía municipal y a la policía de tránsito nada efectiva, en donde a su vez la corrupción es un elemento que merma de manera directa la estructura y funcionamiento de ambas instituciones.

La estructura de las instituciones mexicanas se encuentra débil y fracturada por la corrupción y para que posea un mejor funcionamiento se necesita una reestructuración en todos los niveles, federal, estatal y municipal. Asimismo, el enfoque neoinstitucionalista, afirma que las instituciones desempeñan un papel crucial en la dinámica y el desarrollo de las economías en todo momento, ya que de cierta forma las instituciones son las reglas del juego que guían la vida económica, política y social, dichas reglas, explican el éxito o el fracaso, el crecimiento o estancamiento de un sistema económico (Ayala, 2000).

Cabe recordar que el bienestar de la población no sólo se satisface por medio de las instituciones, sino que son las mismas instituciones las que deben insistir al Estado para que brinde más y mejores oportunidades a los habitantes, por ejemplo, el Banco Mundial, el Banco Interamericano de Desarrollo, la Organización para la Cooperación y el Desarrollo Económico y otros organismos internacionales que han identificado a la infraestructura como elemento detonante de desarrollo económico y social.

\section{Infraestructura}

La provisión eficiente de los servicios de infraestructura es un elemento importante dentro de las políticas de desarrollo, especialmente en aquellos países que han orientado su crecimiento hacia el exterior. Ejemplo de ello es el caso de México en donde esta política se dio con mayor énfasis en la adopción del Tratado de Libre Comercio con América del Norte (TLCAN) en 1990. 
Pese a ello, actualmente en México, las condiciones de infraestructura no son realmente de una economía funcional, ya que algunas de las problemáticas que presenta son:

- Regiones con escasa conectividad, lo que genera desigualdades económicas, laborales y sociales.

- Una causa de la pobreza y el débil crecimiento de los niveles de vida, está relacionada con la geografía, puesto que genera dispersión territorial y ocasiona falta de bienes públicos en las comunidades más alejadas (Skoufias, 2009).

- No se avanza en la modernización de la red, tampoco en el desarrollo, ni en la ampliación de infraestructura.

- No se toman en cuenta las necesidades de cada Estado o de la sociedad, lo cual también incentiva a la desigualdad.

- Las políticas de gobierno no tienen como un principal objetivo invertir en infraestructura.

Todas las economías, así como México, requieren ampliar y modernizar su infraestructura básica de acuerdo con estándares tecnológicos internacionales para lograr niveles máximos de cobertura del territorio nacional y satisfacer con eficacia las necesidades de servicios de infraestructura de los agentes económicos y las personas.

Jeffrey Delmon menciona que la falta de infraestructura impide el crecimiento económico de una nación y la competitividad internacional (The World Bank, 2006), cuando un país no posee toda la infraestructura necesaria representa la pérdida de la calidad de vida y el aumento de problemas, tales como muertes y enfermedades (Willoughby, 2004).

Esto lleva a pensar que es totalmente necesario invertir de manera adecuada en los servicios de infraestructura para estimular el crecimiento y reducir la pobreza. Las demandas insatisfechas son enormes y las inversiones no han alcanzado la demanda (The World Bank, 2008).

En México, en el caso de la Red carretera, el ICG la ubica en el lugar número 58 de 138 y con una calificación de 4.3, no tan mala posición si 
se compara con países como El Congo o Paraguay que lejos de que mejore la calidad de las carreteras han ido empeorando, pero se debe tomar en cuenta que en México, tanto la inversión pública como la privada, han fluctuado año con año, sin embargo, no han dejado de fluir como se muestra en la gráfica 5 .

\section{Gráfica 5. Inversión pública y privada en infraestructura carretera (millones de pesos)}

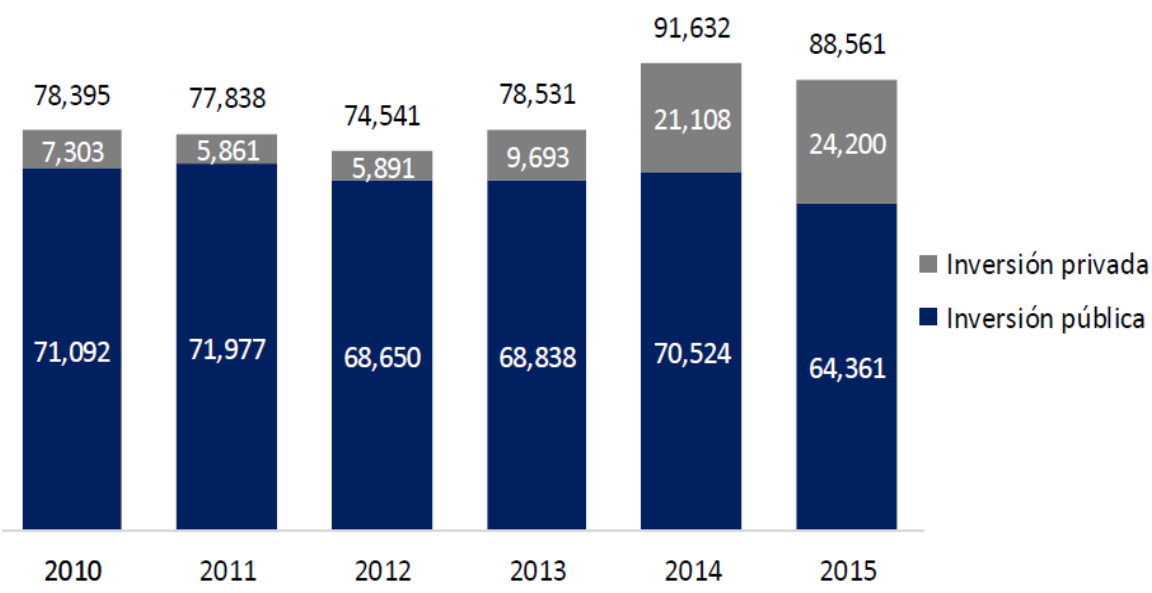

Fuente: Principales estadísticas del sector comunicaciones y transportes 2015, SCT.

Según datos de la Secretaría de Comunicaciones y Transportes (SCT) para 2010 la inversión pública y privada sumó un total de 78,400 millones de pesos, mientras que para 2015 ambas inversiones sumaron un total de 88,600 millones de pesos, en donde la inversión pública aportó poco más de 64 millones de pesos, y la privada poco más de 24 millones de pesos, es decir hubo un aumento del 13\% de un año respecto de otro año.

Los esfuerzos que se han llevado a cabo no son suficientes, en este rubro se debe avanzar en la modernización de la red carretera, dar impulso al desarrollo y a la ampliación de las vías y tomar en cuenta las necesidades de cada entidad, de acuerdo a las actividades en las cuales destaquen o tengan mayor debilidad económica. 
Por su parte, la infraestructura Portuaria de México está catalogada con una calificación de 4.4 y en la posición número 57 , la cual se ha mantenido constante de cierta forma. No así la inversión, pese a que ha aumentado de 2010 a 2015, su mayor repunte fue en 2012 al llegar hasta 12,400 millones de pesos, además dentro de esta infraestructura, la inversión privada es la de mayor participación en comparación con la pública, sumando un total de 33,700 millones de pesos, cerca de 900 millones de pesos más que la inversión pública (gráfica 6).

\section{Gráfica 6. Inversión pública y privada en infraestructura portuaria (millones de pesos)}

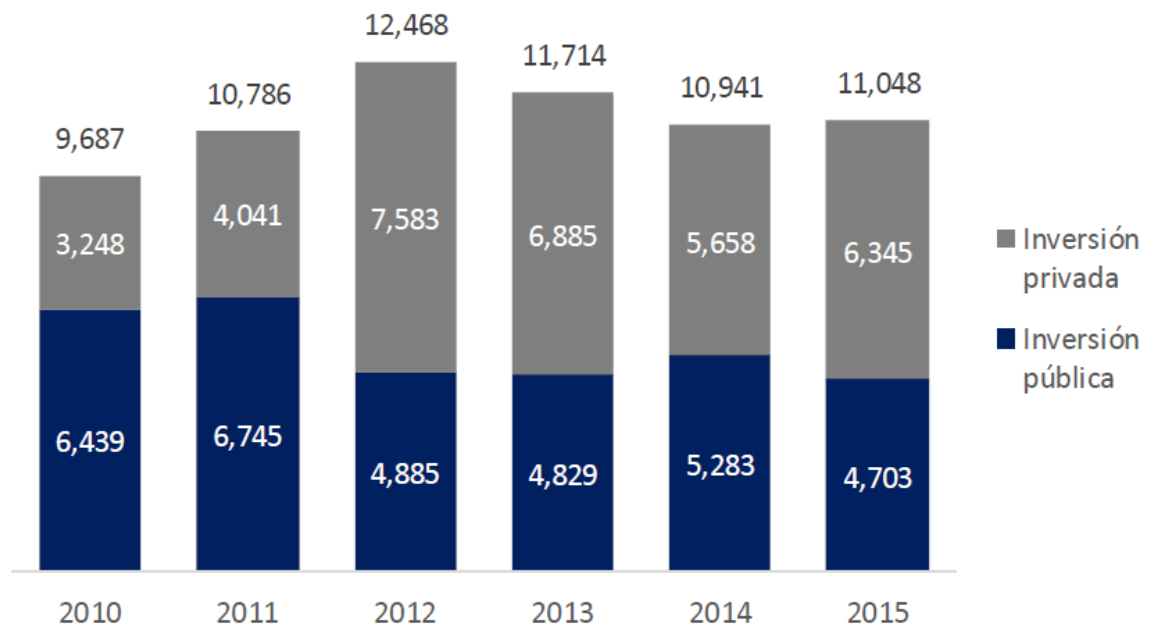

Fuente: Principales estadísticas del sector comunicaciones y transportes 2015, SCT.

Es necesario acrecentar ambos tipos de inversiones, pero también la pública. Asimismo, es importante aumentar la capacidad y la conectividad entre puertos, las ampliaciones de los puertos de tamaño intermedio deben ser sustanciales para el crecimiento de actividades de alcance regional y local de acuerdo a su orientación de negocios. El desempeño operativo también debe ser tomado en cuenta para reducir los tiempos de movimiento de carga, comercialización y transportación, con el objetivo de disminuir las tarifas. 
La infraestructura aeroportuaria es también otro rubro que el ICG identifica como importante en la infraestructura de una economía; en el caso mexicano tiene una calificación de 4.6 y la posición número 61 dentro del índice, la cual ha sufrido un ligero descenso, pero quizá se verá una mejoría al concluir la construcción e iniciar las actividades del NAICM (Nuevo Aeropuerto Internacional de la Ciudad de México). Por lo pronto la red de aeropuertos cuenta con 63 para servicio internacional, 13 en servicio nacional y 1,408 aeródromos, en donde la inversión ha aumentado de manera notoria. Aunque a causa del proyecto mencionado, NAICM, no ha crecido en su totalidad para avanzar en materia de modernización y ampliación de la infraestructura aeroportuaria existente (gráfica 7).

\section{Gráfica 7. Inversión pública y privada en infraestructura aeroportuaria (millones de pesos)}

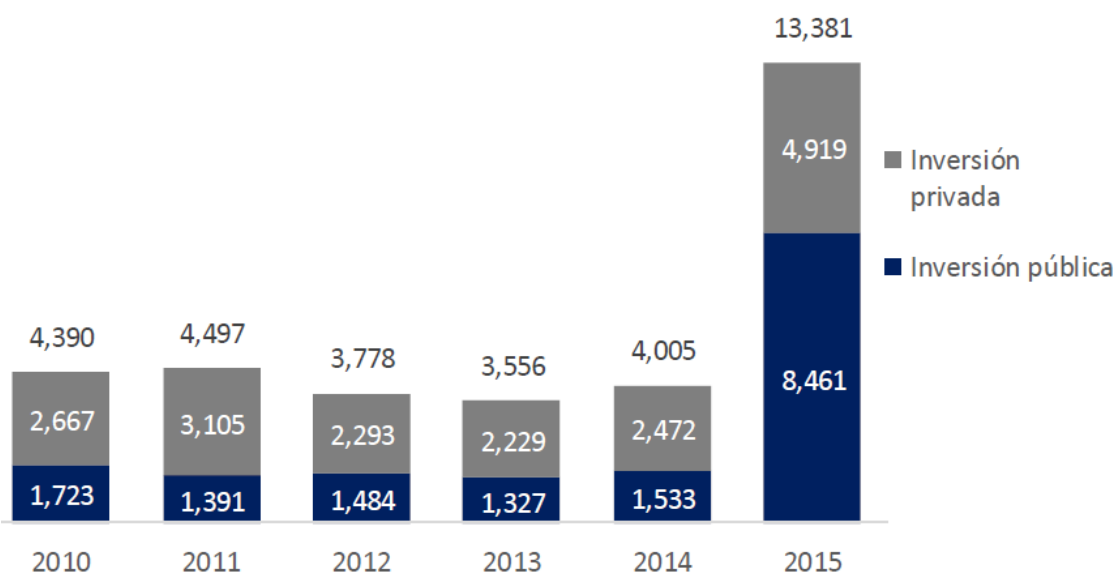

Fuente: Principales estadísticas del sector comunicaciones y transportes 2015, SCT.

Los datos oficiales de la SCT en 2015 arrojan que hubo un crecimiento de las inversiones, de 2010 a 2015 , de más del 200\%, pasando de 4,400 millones de pesos a 13,400 millones de pesos, siendo la inversión pública de mayor presencia con 8,461 millones de pesos y 4,900 de inversión privada. 
En materia aeroportuaria es importante mejorar de manera general la infraestructura, la cual debe promover la inversión oportuna de concesionarios en los aeropuertos del país, de modo que sus condiciones de servicio sean óptimas. En cuanto al NAICM, se debe llevar a cabo un seguimiento puntual y específico a la terminación y puesta en marcha; asimismo, asegurar la conectividad y operabilidad de los diferentes medios de transporte que interactuarán en conjunto con el NAICM. El tema de infraestructura en México tendrá que contemplar proyectos alternativos que contengan estrategias en torno a la comunicación, el comercio, la industria y el bienestar económico y social de cada región.

La ausencia de infraestructura adecuada, así como la provisión e instalación ineficiente de servicios de infraestructura, por ejemplo, en educación, salud, caminos, carreteras, deportivos, y muchos más, es un obstáculo para generar políticas de desarrollo y tasas de crecimiento competitivo a nivel internacional. En este caso el WEF consideró seriamente el impacto en vías de transporte, y la que tiene que ver con electricidad y telefonía, ya que estos elementos crean redes de infraestructura que contribuyen a generar la integración del sistema económico y geográfico de un país.

Si dicha infraestructura se da de manera transversal y longitudinal, abarcando el territorio a través de medios de interconexión, se puede dar el acortamiento de distancias, la disminución de tiempos de una región a otra, y el desarrollo evolutivo de los sectores, la actividad económica del país y, por tanto, la reducción de la desigualdad en ingresos.

La dependencia de infraestructura en electricidad y telefonía y el establecimiento de las mismas proporciona libertad para trabajar, estudiar y desempeñarse en todo tipo de actividades de la vida diaria del ciudadano y las empresas, por ello, es esencial establecer vías de telecomunicación eficientes que garanticen la comunicación de los habitantes de una nación desde cualquier distancia. 


\section{Eficiencia en el mercado laboral}

En una economía el mercado laboral eficiente es el que tiene flexibilidad laboral o desregulación en el mercado de trabajo, lo cual quiere decir que se eliminan o modifican algunos derechos laborales para facilitar la contratación o la despedida de la fuerza de trabajo de parte de las empresas, por supuesto deben ser en favor de los empleados por medio de contratos laborales.

Las regulaciones que marcan las instituciones del mercado laboral toman en cuenta que la compra-venta de la fuerza de trabajo y sus condiciones se definen para un periodo específico y no se trata de un cambio de propiedad ni total ni permanente, pese a que en ocasiones existen contratos que lo especifiquen. Existen además problemas de información incompleta al no saber la empresa qué es lo que en verdad va a recibir del trabajador y viceversa; afectando la movilidad laboral y la inversión en capital humano (Weller, 2007).

Por otro lado, la manera en la cual el talento disponible es usado en favor de la empresa y, por ende, de la economía, es otra característica que debe ser tomada en cuenta para eficientar el mercado de trabajo, considerando, entre otras cosas, la capacidad de atraer talentos, la participación femenina en las actividades económicas, la paga y la productividad de la fuerza de trabajo. Es posible que, mientras existan incentivos laborales, posibilidad de desarrollo dentro de la empresa, premio al mérito y demás prestaciones laborales sin esquemas desiguales (hombres vs mujeres), el nivel de competitividad y eficiencia de la población en cuestión laboral aumentará.

La flexibilidad y la eficiencia en el mercado laboral son vehículos importantes de competitividad, mencionados anteriormente, éstos garantizan que los trabajadores con mayor preparación y capacitación son asignados eficientemente en un puesto de trabajo en la empresa y la economía. A cambio, es importante dotar a la fuerza de trabajo de horarios flexibles en los cuales desempeñen las capacidades del capital humano de manera eficiente y no al contrario, situación que afectaría a la empresa en el puesto que desempeña el trabajador. 
Además de ofrecer turnos flexibles de trabajo, es conveniente ofrecer incentivos para los empleados, no sólo económicos, sino también de género. México se ha encontrado con ciertas problemáticas dentro de este séptimo pilar, las cuales son:

- El mercado laboral no es flexible, al contrario, los esquemas laborales son rígidos.

- La integración de las PyMes no es una prioridad pese a que ésta puede ser una estrategia laboral que genere cadenas productivas globales y mejores empleos remunerados.

- No se facilita la relación entre las instituciones educativas y las laborales, es decir no existen programas que detonen fuertemente en el futuro de los egresados.

- Hace falta implementar una política que obligue a las empresas a la formalización laboral, ya que esto trae como resultado mayores niveles de aprendizaje, capacitación, contratos laborales y, con ello, una regulación laboral.

- México debería alentar la preparación en talleres y las certificaciones de mano de obra para diversos oficios, remarcando que, entre mayor preparación y destreza, mayor sueldo.

- Las jornadas de trabajo son muy largas, no se considera que entre más larga la jornada de trabajo menor es la productividad y eficiencia.

\section{Preparación tecnológica e innovación}

Estos pilares de preparación tecnológica e innovación, que son el 9 y el 12 respectivamente, suelen colocarse de manera conjunta, no porque no guarden relación con los demás existentes sino que se puede decir que un pilar se respalda del otro para obtener recursos y vías que hagan más eficiente su desempeño y funcionamiento, de este modo, la preparación tecnológica de un país es por medio del desarrollo tecnológico, tomando en cuenta la infraestructura que posee, tiene que ver con elementos como la adopción o adquisición de tecnología, así como el uso de las 
Tecnologías de la Información y la Comunicación (TIC’s) y, por supuesto, la innovación.

Según la descripción del WEF, el pilar mide la agilidad con la que una economía adopta las tecnologías existentes para mejorar la productividad de sus industrias, con especial énfasis en su capacidad para aprovechar plenamente las TIC's en las actividades diarias y en los procesos de producción. Mientras que la innovación del WEF es particularmente importante para las economías cuando se acercan a las fronteras del conocimiento, y la posibilidad de generar más valor con sólo la integración y adaptación de tecnologías exógenas; además, incluye factores de estudio como la capacidad de innovación, la calidad de las instituciones de investigación, el gasto en Investigación y Desarrollo (I+D), la colaboración de las universidades con las industrias en $\mathrm{I}+\mathrm{D}$, la adquisición de productos de tecnología avanzada, disponibilidad de ingenieros y científicos $\mathrm{y}$, por último, las solicitudes de patentes al $\mathrm{PCT}^{8}$.

Estos factores son necesarios porque no sólo ayudan a generar nuevo conocimiento tecnológico, sino que también se amplía la frontera de conocimiento, misma que puede ampliarse sin llegar a encontrarse con rendimientos decrecientes, ya que los elementos en este pilar siempre están transformándose para su mejora, o bien para ser reemplazados por algo mejor, situación que resulta positiva al avanzar en el desarrollo y así continuar a la vanguardia en procesos y productos, para mantener un nivel de competitividad creciente o al menos constante.

Por su parte, Pilat y Lee (2001) señalan que las TIC generan un impacto directo sobre variables como el crecimiento económico, la productividad total de los factores o la eficiencia técnica del sector manufacturero. En este contexto, es imprescindible mencionar que para que un país se distinga, debe llevar a cabo investigación de frontera,

8 El Tratado de Cooperación en materia de Patentes ofrece asistencia a los solicitantes que buscan protección internacional por patente para sus invenciones y asiste a las Oficinas con las decisiones sobre el otorgamiento de patentes, así como pone a disposición del público el acceso a la extensa información técnica en relación a las invenciones. 
apoyándose en la ciencia, la innovación y el uso de dichas técnicas de investigación, de forma contraria se arrastrarán brechas de desigualdad y conocimiento, que al paso del tiempo se transforman en la incapacidad de poder acceder a un mundo competitivo.

En el caso de México, el pilar de preparación tecnológica ocupa la posición número 73, siendo este pilar el de menor desempeño en comparación con los demás dentro del subíndice (promotores de eficiencia), a pesar de que para el último año mejoró su posición, el Estado debe mantener la atención en él.

La Encuesta Nacional sobre Disponibilidad y Uso de Tecnologías de la Información en los Hogares llevada a cabo por INEGI en 2015, dice que el uso de las TIC es un fenómeno urbano, ya que en las $32^{9}$ ciudades seleccionadas el $59.5 \%$ de los hogares dispone de computadora y el $56.2 \%$ cuenta con conexión a Internet.

Más a detalle, en el Distrito Federal, Nuevo León, Sonora y Baja California, 6 de cada 10 hogares disponen de computadora, en contraste, en Guerrero, Oaxaca y Chiapas, menos de una cuarta parte cuentan con tal dispositivo, en tanto que se tiene disponibilidad de Internet en 12.8 millones de hogares (39.2\% de los hogares a nivel nacional), pese a que el número de hogares con internet ha aumentado cerca del $40 \%$ de 2010 a 2015, aún falta hacer esfuerzos para dotar de dicho servicio a la mitad restante de la población.

Otro servicio de tecnología que vale la pena destacar es el de la telefonía celular, servicio que posee mayor aceptación entre la población en general, la misma encuesta citada anunció que a nivel nacional, el $71.5 \%$ es usuaria de dicho servicio. En cinco entidades, la proporción es superior al 80.0\%: Quintana Roo, Sinaloa, Baja California, Sonora y Baja California Sur. Solo en cuatro entidades este valor es inferior a 60.0\%: Puebla, Oaxaca, Chiapas y Guerrero.

932 ciudades seleccionadas, correspondientes a la población de seis años o más, a partir de un tamaño de muestra de 90,030 viviendas distribuidas en todo el país. 
Algunos especialistas en el tema, por ejemplo, Stiroh (2002; 2004) demostró empíricamente que el uso de información tecnológica por parte de empresas y trabajadores aumentaba significativamente la productividad laboral y la eficiencia de las empresas. Es importante pensar que la innovación tecnológica es conveniente para todos los países, puesto que se da en todos los sectores, incluyendo el sector salud, el cual es clave para el bienestar social. Se puede hablar entonces de diferentes y nuevos accesos a oportunidades.

Como ya se mencionó, de la mano con la preparación tecnológica se encuentra la innovación, que para el ICG 2016 ocupó el lugar número 55 , con una calificación de 3.4, desempeño similar a países como Tailandia en la posición 54 y la Federación Rusa en la posición número 56. Un país que posea fortaleza en el ámbito de la innovación, no sólo tendrá mayor escala de productividad, sino también tendrá la capacidad de enfrentar y adaptarse a las fluctuaciones económicas que se generan en el entorno global.

\section{Cuadro 3. Beneficios de la innovación en una Economía}

\begin{tabular}{|c|l|}
\hline Actores & \multicolumn{1}{c|}{ Beneficios de la innovación } \\
\hline Consumidores & $\begin{array}{l}\text { - Se traduce en mejores productos y servicios, en términos de calidad, } \\
\text { diseño, precio y eficiencia. }\end{array}$ \\
\hline Empresas & $\begin{array}{l}\text { - Trae una mayor rentabilidad derivada de la posibilidad de diseñar y } \\
\text { producir nuevos o mejores bienes y servicios o de utilizar técnicas pro- } \\
\text { ductivas más eficientes que las de sus competidores. } \\
\text { - Las empresas que innovan cuentan con el conocimiento necesario para } \\
\text { dar respuesta rápida y eficaz a las oportunidades de la globalización. } \\
\text { - Crecimiento sostenido y capacidad de enfrentar amenazas competitivas } \\
\text { de sus rivales. }\end{array}$ \\
\hline Sociedad & $\begin{array}{l}\text { - Genera nuevo conocimiento y soluciones a problemas relacionados con } \\
\text { la salud, el medio ambiente, la pobreza, la seguridad, entre otros. } \\
\text { - Lograr un crecimiento económico sostenido al estar sustentado en me- } \\
\text { joras en productividad. } \\
\text { - Mejora la calidad de vida de las personas. }\end{array}$ \\
\hline
\end{tabular}

Fuente:Programa Nacional de Innovación Comité Intersectorial para la innovación, 2011. 
Los beneficios descritos en el Cuadro 3 solo son algunos, también el hecho de innovar ayuda a dar pasos más largos a la Economía para adaptarse a las transformaciones constantes en el mundo internacional.

En la actualidad, la sociedad se orienta hacia la información y el conocimiento, las organizaciones se ven influenciadas por una creciente y más fuerte tecnología de información que afectan de alguna manera a los procesos económicos y empresariales; de hecho el acoplamiento entre la tecnología y el negocio se está configurando como una de las fuentes de creación de valor en las empresas, así como de generación de innovación y, por ende, en un factor de ventajas competitivas (Moraleda, 2004).

Asimismo, Mathison y Gándara (2007) mencionan que es importante acentuar la innovación de las empresas, entendiendo por innovación la capacidad para transformar los procesos empresariales y crear organizaciones más competitivas, ágiles y eficaces. De esta misma forma López (2004) dice que los fenómenos de innovación tecnológica no solo inciden sobre la productividad de los factores, sino que han desencadenado y desencadenarán profundos procesos de transformación en las economías y en la sociedad de los países que las han adoptado. Sin embargo, es complicado alcanzar niveles altos de innovación ya que interfieren situaciones como las externalidades, fallas de información y disponibilidad de recursos y la coordinación entre sectores. Algunas de las problemáticas inmersas dentro de estos dos pilares se encuentran las siguientes:

- Hace falta el uso y aprendizaje constante de las TIC's, de otra forma es también un elemento de desigualdad al dejar en el rezago a cierto número de población por no brindarle la enseñanza adecuada.

- Las autoridades encargadas de la educación no se preocupan por desarrollar habilidades y destrezas del alumno en el campo laboral, esto incluye el aprendizaje de idiomas y el uso constante de las TIC's, lo cual se puede llevar a cabo en actividades extracurriculares. 
- La innovación y sofisticación no son una prioridad al únicamente aportar un $0.52 \%$ de su PIB, en comparación con Suiza que aporta un $6 \%$ de su PIB (Banco Mundial).

- No existe un proyecto estructurado que defina las estrategias a seguir, esto es importante en un país ya que sienta las bases de los objetivos y propósitos.

- El gasto propuesto para la función ciencia, tecnología e innovación, en el ejercicio fiscal 2016 obtuvo una reducción del 3.66\% con respecto al aprobado por la Cámara de Diputados en el 2015; y de $3.54 \%$ en comparación al propuesto por el Ejecutivo Federal para el ejercicio fiscal 2015 (PEF).

Estos puntos descritos son sólo algunos de los problemas que giran en torno al uso de la tecnología y al desempeño de la innovación, es importante considerar que los planes y proyectos de inversión deben ser cada vez mayores para todo el país al tomar en cuenta las necesidades de los Estados, ya que cada uno se desempeña de manera distinta aun cuando se encuentren juntos o en el mismo escenario comercial y económico.

De manera adicional en el cuadro 4 se enlistan tres pilares en los cuales México puede y debe avanzar, tomando medidas y realizando acciones encaminadas a mejorar la cobertura, eliminar las ineficiencias y compensar los posibles desequilibrios que se generan en los temas concernientes a dichos pilares.

\section{Cuadro 4. Problemática en México en tres pilares específicos}

\begin{tabular}{|c|l|}
\hline Pilar & \multicolumn{1}{c|}{ Problemática } \\
\hline $\begin{array}{c}\text { 4. Salud y } \\
\text { Educación } \\
\text { Primaria }\end{array}$ & $\begin{array}{l}\text { - Según la OCDE, México es uno de los tres únicos países que no ha logrado } \\
\text { todavía una cobertura de salud universal (junto con Estados Unidos y Turquía). } \\
\text { - Asimismo, el gasto complementario en bienes y servicios de salud repre- } \\
\text { senta aún el 4.5\% del consumo final de los hogares en México, un 50\% más } \\
\text { que el promedio de la OCDE (OCDE, 2011). } \\
\text { - Cabe destacar que las áreas rurales son las de mayor afectación en cuestión } \\
\text { de cobertura en salud, al no haber suficientes médicos en el país: la tasa es de } \\
\text { dos médicos por cada 1000 es algo alarmante. } \\
\text { - Las campañas contra la diabetes, el sida, el embarazo no deseado, entre otros, } \\
\text { son escasas o insuficientes, muchas veces no logran el objetivo esperado. }\end{array}$ \\
\hline
\end{tabular}




\begin{tabular}{|c|c|}
\hline & $\begin{array}{l}\text { - Los alumnos, así como los profesores de todos los niveles académicos de- } \\
\text { ben ser sometidos a pruebas constantes, situación que no sucede en México } \\
\text { de manera cotidiana. } \\
\text { - La oferta educativa debería estar alineada con la oferta de empleo dispo- } \\
\text { nible en el país y de acuerdo también a las necesidades por sector a nivel } \\
\text { nacional. } \\
\text { - Debería existir un mayor número de becas y mecanismos de entrada en } \\
\text { instituciones de prestigio (privadas) para alumnos que no pueden acceder tan } \\
\text { fácil a este tipo de educación. } \\
\text { - No posee indicadores de transparencia académica en cuanto al desempeño } \\
\text { de una institución a otra, sobre todo en el caso de la educación media supe- } \\
\text { rior y la superior, por lo tanto, no se tiene información certera de los resulta- } \\
\text { dos académicos en general para cada alumno. }\end{array}$ \\
\hline $\begin{array}{l}\text { 5. Edu- } \\
\text { cación } \\
\text { Superior y } \\
\text { Capacita- } \\
\text { ción }\end{array}$ & $\begin{array}{l}\text { - Tan sólo el } 18.6 \% \text { (datos SEP) de la población tiene educación superior } \\
\text { en } 2016 \text {. } \\
\text { - } 52 \% \text { de los mexicanos tienen estudios a nivel secundaria, la población estu- } \\
\text { diantil se está quedando estancada en un rango educativo (SEP). } \\
\text { - Los estudiantes no poseen los conocimientos necesarios para obtener mejo- } \\
\text { res oportunidades de empleo y por lo tanto mejor remuneración. } \\
\text { - Los estímulos académicos han ido en aumento, pero la calidad de la educa- } \\
\text { ción y la preocupación por la misma se ha quedado estancada. } \\
\text { - La cobertura en educación superior debe ser tomada en cuenta, en Estados } \\
\text { donde la cobertura sea inferior al } 20 \% \text { por ejemplo, Guerrero, Oaxaca y } \\
\text { Quintana Roo (SEP). } \\
\text { - No existe un consenso organizacional entre los diferentes niveles de gobier- } \\
\text { no, tomando en cuenta las necesidades educativas y las diferencias existentes } \\
\text { en los diversos estratos sociales. } \\
\text { - No existe una colaboración estrecha entre escuelas y organizaciones empre- } \\
\text { sariales, lo cual dificulta la búsqueda y encuentro de un trabajo. } \\
\text { - A los bachilleratos técnicos les hace falta mayor promoción y fomento, } \\
\text { siendo de las mejores alternativas de estudio de Educación Media Superior. } \\
\text { De acuerdo al BID, el } 72 \% \text { de las empresas aseguran que el nivel académico } \\
\text { y tecnológico de los alumnos de CONALEP es alto (IMCO, 2016). }\end{array}$ \\
\hline $\begin{array}{l}\text { 11. Sofisti- } \\
\text { cación de } \\
\text { los } \\
\text { Negocios }\end{array}$ & $\begin{array}{l}\text { - Algo que a México le hace falta fortalecer son los esquemas de financia- } \\
\text { miento para emprendedores, pues muchas veces no existen o son muy difíci- } \\
\text { les de acceder a estos, es por ello que tanto el negocio como el financiamiento } \\
\text { deben ir de la mano desde el inicio hasta acceder al mercado. } \\
\text { - Los esquemas de asignación crediticia deberían generar incentivos para } \\
\text { crear empresas y fortalecerlas o modernizarlas, también para el desarrollo de } \\
\text { proyectos que generen valor a la economía. }\end{array}$ \\
\hline
\end{tabular}




\begin{tabular}{|l|l|}
\hline Deben existir más talleres de capacitación en toda materia empresarial, des- \\
de capital humano, gerencia, administración, emprendedurismo, entre otros. \\
• El Estado debe promover y favorecer la competencia, otorgando también \\
los recursos y herramientas necesarias según la empresa se vaya desarro- \\
llando. \\
- Los programas de PyMes deberían ser ligados con capital privado, con el \\
fin de facilitar el financiamiento y la entrada de dicho proyecto a mercados \\
nacionales e internacionales.
\end{tabular}

Fuente: Elaboración propia.

La problemática descrita trata de ser enunciativa más no limitativa, se entiende que los problemas del país son multifactoriales. Un tema que se puede inferir consiste en la dificultad que tiene el país de operar una política a nivel nacional dada la poca convergencia que tienen las entidades federativas entre sí10 ${ }^{10}$. En el mejor de los casos para avanzar en materia de competitividad es necesario que los esfuerzos resulten ampliamente inclusivos.

Como principales propuestas a considerar, se establece que la dispersión de las principales zonas industriales y comerciales necesitan estar conectadas a través de infraestructura eficiente, por ejemplo conectar los corredores carreteros, agilizar la actividad portuaria por medio de la ampliación de los puertos comerciales, construcción y modernización de caminos y puentes de zonas rurales, generando polos de desarrollo económico y social, con miras a reducir la desigualdad.

10 Ramírez (et. al., 2017), realizando un estudio sobre Federalismo Fiscal encuentra que las entidades federativas en México en lugar de tener una senda de convergencia han ampliado las brechas entre ellas, México se compone de entidades federativas que avanzan a diferentes velocidades y eso no sería un problema real ya que en el tiempo la discontinuidad es lo que permitiría la convergencia, en realidad el problema consiste en que las entidades con mejores condiciones económicas han tenido un desempeño mejor. Por lo cual a pesar de las redistribuciones que se hacen desde la Federación cada año se amplía la diferencia entre ellas, denotando que no existe un poder común, usos y costumbres similares, desarrollo administrativo e institucional semejante, etc. Bajo esa perspectiva las políticas públicas, económicas y sociales encuentran dificultades en el logro de sus objetivos. 
Por otro lado, tanto las instituciones como la corrupción deben ser tratadas al mismo tiempo por medio de una reestructuración de fondo de las actividades que se llevan a cabo en cada dependencia para eliminar puestos o plazas duplicadas. Asimismo, revisar a conciencia año con año la funcionalidad del Presupuesto económico y la forma en cómo se está ocupando, especialmente en el caso de proyectos sociales y sueldos de funcionarios.

Además, es también de importancia haber creado el Sistema Nacional Anticorrupción, este debe tener todas las atribuciones y facultades para imponer, modificar y vigilar los tramos de control que eviten las prácticas corruptas, además de verificar que sean castigadas de manera drástica, para que este tipo de actividades no queden impunes y no se siga propagando a diferentes escalas la corrupción que tanto daño causa al ingreso nacional presente y futuro.

\section{Conclusiones}

A manera de conclusión se pueden resaltar varias ideas, entre ellas, la importancia que poseen los índices junto con los indicadores económicos, los cuales sirven de base para diagnosticar qué tan mal se encuentra una economía y cómo es que las políticas o la toma de decisiones puede influir para mejorar las condiciones de vida de la población y del país, sobre todo en un contexto de constantes cambios.

En un mundo globalizado donde la interacción entre países, en términos de intercambio y de producción, cada vez se vincula en mayor cuantía, es esencial mantener niveles de competitividad similares, lo cual se garantiza en primera instancia estableciendo parámetros de medición debidamente estandarizados y posteriormente manteniendo dichos parámetros al menos en el promedio internacional.

México a través de los años ha perdido posiciones en el ICG, siendo los pilares más susceptibles los ocho mencionados en el trabajo y, por ello, es necesario dedicar atención especial a tales temas. 
¿Qué es lo que queda pendiente? Para el caso de México es deseable concretar los esfuerzos en los cinco pilares relativos a las instituciones, a la infraestructura, la eficiencia del mercado laboral, la preparación tecnológica y la innovación; realizar mayor investigación respecto a las causas que impiden un mejor desempeño en esos temas, así como de las políticas y acciones que deben hacerse para avanzar en las propuestas, que sirvan para mejorar la condición competitiva del país; debe aprenderse de quien lo hace bien, lo cual implica no el copiar los modelos actuales si no entender qué es lo que hace que funcionen y cuáles son las condiciones y características de México para llevarlos a cabo.

Es importante, por otra parte, tener en cuenta que en algunos casos será relativamente rápido encontrar mecanismos de solución a las restricciones establecidas, pero en otros las medidas de política ofrecerán resultados de mediano o largo plazo, por lo que la sociedad deberá ser paciente y mantener los esfuerzos en la misma dirección para concretar los objetivos que serán visibles en la medida que avancemos en las posiciones y puntajes del ICG.

\section{Bibliografía}

Arellanes, Paulino, "La empresa trasnacional sinónimo de globalización”, Revista Mexicana de Ciencias Politicas y Sociales, Revistas UNAM, 1996, pp. 91-112.

Ayala, José, "Instituciones y desarrollo económico de México", Revista de Comercio Exterior, Bancomext, 2000, pp. 95- 2016.

Brunet, Belzunegui, Empresa y estrategia en la perspectiva de la competitividad global, Editorial Ariel, España, 2000, p. 252.

Casar, Maria, México: Anatomía de la Corrupción, Instituto Mexicano de la Competitividad, CIDE-IMCO, México, 2015, p. 66.

Cavalli, Alessandro, "Instituzione", en Enciclopedia delle scienze sociali, Instituto della Enciclopedia fondata da Giovanni Treccani, Roma, 1996, pp. 122-134. 
Douglass, North, Institutions, Institutional Change and Economic Performance, Cambridge Univ Press, Inglaterra, 1990, p. 152.

Estrada, José. y Landa, Heri, La cooperación entre Corea del Sur y América Latina a través de los acuerdos comerciales y de inversión, Análisis Económico, Revistas UNAM, México, 2007, pp. 197-228.

Gallino, Luciano, "Instituzione", en Dizionario di socilogia, Italia, 1993, pp. 387-390.

García, Maximiliano, "Políticas de innovación científica y tecnológica de América Latina", Encrucijada, Revistas UNAM, México, 2011, pp. 1-12.

González, Alfonso, La innovación: un factor clave para la competitividad de las empresas, Innovatec, Dirección General de Investigación, Consejería de Educación de la Comunidad de Madrid, España, 2000, p. 170.

Krugman, Paul, El internacionalismo moderno, Editorial Crítica, Barcelona, España, 2004, p. 171.

Landa, Heri y Arriaga, Rosalinda, "Crecimiento, Competitividad y restricciones externas en América Latina”, Investigación Económica, México, 2017, pp. 53-80.

Levitan, Sar y Diane, Werneke, "Productivity: Problems, prospects, and policies", The Johns Hopkins University Press, United States, 1984, p. 125.

López, José, ¿Pueden las Tecnologías de Información mejorar la Productividad?, Universia Business Review, Portal Universia S. A. España, 2004, pp. 82-95.

Mathison, Luis, Innovación: factor clave para lograr ventajas competitivas. Negotium, Ciencias Gerenciales, Venezuela, 2007, pp. 46-83.

Moraleda, Amparo, "La innovación: Clave para la competitividad empresarial”, Universia Business Review, Portal Universia S.A. España, 2004, pp. 128-136. 
Peralta, Alberto, La economía del conocimiento: oportunidad para el desarrollo de México, Encrucijada, FCPyS, UNAM, México, 2011, p. 14.

Pilat, Dirk, Productivity growth in ITC-producing and ITC-using industries: a source of growth differentials in the OECD?, OECD Science, Technology and Industry Working Papers, OECD, Paris, 2001, p. 51.

Porter, Michael, Instituciones para la competitividad en Colombia: marco conceptual, Proyecto Andino de Competitividad, Corporación Andina de Fomento, Colombia, 2001, p. 9.

Porter, Michael, La ventaja competitiva de las naciones, Plaza \& Janés, España, 1991, p. 1056.

Ramírez E, et. al. Eficiencia y equidad en el federalismo mexicano, una primera aproximación, 2017.

Rozas, Patricio, "Desarrollo de infraestructura y crecimiento económico: revisión conceptual", División de Recursos Naturales e Infraestructura, CEPAL, Santiago de Chile, 2004, p. 75.

Salas, Carlos, Cómo medir la asociatividad y la cooperación empresarial. Fondo concursable de donaciones para la competitividad de las PyMes en Centroamérica y República Dominicana, INCAE-BID/ FOMIN, República Dominicana, 2006, pp. 1-15.

Skoufias, Emmanuel, "Determinantes de las Desigualdades Regionales de Bienestar al Interior de los Países de América Latina", Banco Mundial, México, 2009, p.120.

Stiroh, Kevin, Information technology and the U.S. productivity revival: wath the industry data say?, American Economic Review, United States, 2002, pp. 1559-1576.

Stiroh, Kevin, Reassessing the Impact of IT in the Production Function: A MetaAnalysis and Sensitivity Tests. Federal Reserve Bank of New York, United States, 2004, pp. 1-40. 
Suñol, Sandra, Aspectos técnicos de la competitividad, Ciencia y Sociedad. Redalyc, Instituto Tecnológico de Santo Domingo, República Dominicana, 2006, pp. 179-198.

The World Bank, Infrastructure at the crossroads : lessons from 20 years of World Bank experience, The International Bank for Reconstruction and Development, Washington DC, United States, 2006, p. 168.

The World Bank, World Bank Group Sustainable Infrastructure Action Plan Fiscal Years 2009-2011, The International Bank for Reconstruction and Development, Washington, DC. Estados Unidos, 2008, p. 170.

Vandana, Chandra, Innovación y crecimiento, en busca de una frontera en movimiento, Estrategia de Innovación de la OCDE, OCDE, México, 2012, p. 278.

Weller, Jurgen, La flexibilidad del Mercado de trabajo en América Latina y el Caribe: Aspectos del debate, alguna evidencia y politicas, CEPAL, Naciones Unidas, Santiago de Chile, 2007, p. 78.

Willoughby, Christopher, Infrastructure and the Millennium Development Goals, Complementarity of Infrastructure for Achieving the Millennium Development Goals, United Nations, Germany, 2004, pp. 64-75.

\section{Referencias Web}

Consulta Mitofsky (2016), "México: confianza en instituciones 2016", Encuesta Nacional en Viviendas, México. Disponible en: http:// www.consulta.mx/index.php/estudioseinvestigaciones/mexicoopina/item/884-mexico-confianza-en-instituciones-2016 [Consultado agosto, 2017].

Banco Mundial Datos Banco Mundial. Disponible en: http://datos.bancomundial.org/ [Consultado noviembre, 2016] 
Foro Económico Mundial, Índice de competitividad global 2015 y 2016. Disponible en: http://reports.weforum.org/global-competitiveness-report-2015-2016/ [Consultado marzo, 2017].

Instituto Nacional de Estadística y Geografía, Encuesta Nacional de Victimización y Percepción sobre Seguridad Pública (ENVIPE), 2015. Disponible en: http://www.beta.inegi.org.mx/proyectos/enchogares/regulares/envipe/2015/ [Consultado enero, 2017].

Instituto Federal de Telecomunicaciones, Encuesta Nacional sobre Disponibilidad y Uso de Tecnologías de la Información 2015 (ENDUTIH). Disponible en: http://www.ift.org.mx/comunicacion-y-medios/comunicados-ift/es/encuesta-nacional-sobre-disponibilidad-y-uso-de-tecnologias-de-la-informacion-en-los-hogares-2015 [Consultado marzo, 2017].

Organización para la Cooperación y el Desarrollo Económicos, Los Retos de la Salud en México, Participación en el Ciclo de Conferencia y Symposia, México y los indicadores de salud de la OCDE, 2011. Disponible en: https://www.oecd.org/centrodemexico/medios/losretosdelasaludenmexico.htm [Consultado marzo, 2017].

Secretaría de Educación Pública, Sistema Nacional de Información Estadística Educativa. Disponible en: http://www.snie.sep.gob.mx/estadisticas_educativas.html [Consultado marzo, 2017].

Secretaría de Hacienda y Crédito Público, Presupuesto de Egresos de la Federación, 2015 y 2016. Disponible en: http://www.apartados. hacienda.gob.mx/presupuesto/temas/pef/2015/ http://www.pef.hacienda.gob.mx/es/PEF [Consultado marzo, 2017].

Secretaría de Comunicaciones y Transportes. Disponible en: www.sct. gob.mx [Consultado marzo, 2017]. 